\title{
The Proper Criteria for Identification and Sorting of Very Small Embryonic-Like Stem Cells, and Some Nomenclature Issues
}

\author{
Malwina Suszynska, ${ }^{1,2}$ Ewa K. Zuba-Surma, ${ }^{3}$ Magdalena Maj, ${ }^{1}$ Kasia Mierzejewska, ${ }^{2}$ \\ Janina Ratajczak, ${ }^{1,2}$ Magda Kucia, ${ }^{1,2}$ and Mariusz Z. Ratajczak ${ }^{1,2}$
}

Evidence has accumulated that both murine and human adult tissues contain early-development stem cells with a broader differentiation potential than other adult monopotent stem cells. These cells, being pluripotent or multipotent, exist at different levels of specification and most likely represent overlapping populations of cells that, depending on the isolation strategy, ex vivo expansion protocol, and markers employed for their identification, have been given different names. In this review, we will discuss a population of very small embryoniclike stem cells (VSELs) in the context of other stem cells that express pluripotent/multipotent markers isolated from adult tissues as well as review the most current, validated working criteria on how to properly identify and isolate these very rare cells. VSELs have been successfully purified in several laboratories; however, a few have failed to isolate them, which has raised some unnecessary controversy in the field. Therefore, in this short review, we will address the most important reasons that some investigators have experienced problems in isolating these very rare cells and discuss some still unresolved challenges which should be overcome before these cells can be widely employed in the clinic.

\section{Introduction}

$\mathrm{T}$ HE NAME "VERY SMALL embryonic-like stem cells" (VSELs) has been assigned to a rare population of small cells that were initially isolated from murine bone marrow (BM) [1-3]. Subsequently, the presence of cells that phenotypically correspond to VSELs has been reported in multiple murine organs [4]. Finally, small cells that, similar to murine VSELs, are lineage negative ( lin $^{-}$), do not express CD45 antigen $\left(\mathrm{CD} 45^{-}\right)$, and display a primitive morphology (high nuclear/cytoplasm ratio and the presence of euchromatin in nuclei) have been reported in human (i) umbilical cord blood (UCB) [5-8], (ii) mobilized peripheral blood (mPB) [9-13], and (iii) gonads $[14,15]$. Human VSELs isolated from UCB and $\mathrm{mPB}$ are highly enriched in a population of $\mathrm{CD} 133^{+}$cells $[8,16,17]$, and those isolated from gonads were sorted as SSEA-4 ${ }^{+}$cells [18].

Since a VSEL-specific marker has not yet been identified, these developmentally early cells are currently isolated by a multiparameter sorting strategy employing a cocktail of antibodies and proper gating [17,19-22]. Both murine and human purified VSELs express several early-development markers, including Oct-4, Nanog, SSEA-1 (mouse), and
SSEA-4 (human) [1,8,23] and are highly quiescent [24,25] Despite their small size, similar morphological features, and phenotype, VSELs are, to some degree, heterogenous. In particular, cDNA libraries created from purified, doublesorted VSELs (20 cells/library) revealed that these cells, while having a characteristic morphology, small size, and overlapping molecular signature, still differ slightly in the expression of some genes [26]. The best method for assessing the quality of sorted VSELs is the combination of ImageStream analysis, which enables the identification of real, nucleated cell events and excludes those from cell debris, with 7AAD staining, which excludes cells that become damaged during the sorting procedure [19,27].

The best-characterized VSELs at the molecular level using microarray analysis are murine BM-derived VSELs $[23,26,28]$ and small SSEA-4 ${ }^{+}$cells corresponding to murine VSELs isolated from human gonads [14,29,30]. Therefore, more work is needed to characterize molecular signature of VSELs isolated from other murine organs (eg, brain, heart, and skeletal muscles) and, in particular, the phenotypically corresponding populations of human VSELs in BM, UCB, and $\mathrm{mPB}$. The crucial question to ask is whether VSELs are precommitted to monopotent

\footnotetext{
${ }^{1}$ Stem Cell Institute at the James Graham Brown Cancer Center, University of Louisville, Louisville, Kentucky.

${ }^{2}$ Department of Physiology Pomeranian Medial University, Szczecin, Poland.

${ }^{3}$ Department of Cell Biology, Faculty of Biochemistry, Biophysics and Biotechnology, Jagiellonian University, Krakow, Poland.
} 
tissue committed stem cells (TCSCs) in the tissues of their residence.

In this short editorial review, we will address the current validated working criteria for how to properly isolate these rare small cells. This is an important issue, because, as was recently observed, by changing the well-established isolation protocols, an incorrect population of cells was isolated and misidentified as VSELs [31-33]. We will also discuss the relationship of VSELs to other potential pluripotent stem cells (PSCs) and multipotent stem cells (MPSCs), which have been isolated from adult tissues by several other investigators. We noticed that very often cells which correspond to VSELs are given different names [5,6,14,34-38]. Finally, we will also try to justify why we named these cells "embryonic-like," despite the fact that they are isolated from adult tissues.

\section{Multiparameter Sorting of VSELs-How to Avoid Sorting the Wrong Cell Populations}

The current validated strategy for the isolation of cells enriched for VSELs from BM, UCB, or MPB is based on multiparameter sorting of viable small cellular events. Murine VSELs can be isolated as small Sca- $1^{+} \mathrm{Lin}^{-} \mathrm{CD} 45^{-}$ cells, and this approach has been successfully employed not only by us but also by other independent groups [9,39-41] who followed our detailed sorting protocols $[17,19,20,22]$. As reported, the highly quiescent populations of VSELs sorted from murine BM in appropriate experimental settings may give rise to hematopoietic stem cells (HSCs) [42], mesenchymal stem cells (MSCs) [40], lung alveolar type II pneumocytes [39], cardiomyocytes [43,44], and gametes and VSELs isolated from rat BM have been shown to give rise to cardiomyocytes and endothelial cells [45]. Moreover, murine VSELs may support the development of stroma in growing tumors [46]. In parallel, human VSELs have been already shown to become specified into HSCs [47] and MSCs [41].

The detailed protocol on how to sort VSELs by FACS has been described in detail in a chapter in Current Protocols in Cytometry [19]. Unfortunately, a few other groups significantly modified this protocol, which, instead of VSELs, resulted in an incorrect population of sorted cells [31-33]. This has already been the subject of an extensive analysis that we recently published [21]. However, here, we will address some of the most important issues on how to avoid such mistakes in the future.

The major concern with the work of some groups which reported negative data [31-33] is that, despite their claims, they did not follow our published protocol for isolating VSELs. However, we have to admit that these are not trivial sorting strategies, and failure to isolate these rare cells occasionally happens even in our experience in VSELs sorting hands.

The most critical step in VSEL sorting is proper setting of the gate to exclude contamination by cell debris and small erythroblasts. Enrichment in undesired objects may have a critical impact on subsequent genetic and in vitro functional characterization of these cells. Of great importance, despite the presence of anti-glycophorin antibodies (anti-Ter119) employed in the lineage cocktail to deplete murine lineagepositive cells [19], if the wrong gating strategy is employed, it may result in unwanted enrichment of the sorted cells for erythroblasts [32]. In brief, one of the groups [32] failed to isolate murine VSELs because of (i) setting up an enlarged input gate on the FSC versus SSC plot that included granulocytes and apoptotic cells resulted in enrichment of sorted fractions with artifacts, which were reflected in their further analyses (eg, Annexin V binding) and excluded some of the critical very small objects from further sorting; (ii) additional loss of very small objects by their exclusion of VSELs by gating for "singlets"; (iii) employing some selection markers that are unproved as VSEL markers (eg, c-kit); and (iv) focusing on some populations and discarding other fractions (potentially containing VSELs) based on results such as Annexin V binding. For instance, the entire fraction of $\mathrm{CD} 45^{-} / \mathrm{Lin}^{-} / \mathrm{Sca}-1^{+} / \mathrm{c}-\mathrm{kit}^{-} / \mathrm{KDR}^{-}$cells was excluded by these authors from further sorting [32], because it was deemed "apoptotic," while it most likely contained not only real Annexin $V^{+}$FSC $^{\text {low }}$ SSC $^{\text {dim/hi }}$ apoptotic objects, but, in addition, VSELs. Importantly, we have reported [48] that healthy normal cells (including VSELs and HSCs) may bind Annexin V after lysis of RBCs due to microvesicle/microparticle release and posphatydylserine transfer to the membranes of the normal cells. Thus, not all Annexin $\mathrm{V}^{+}$ objects should be interpreted as "apoptotic," as these may represent normal, functional cells [48]. Figure 1 shows a simulation of sorting strategy employed by one of the groups that failed to sort VSELs [32] to demonstrate how important it is to set a proper gate during sorting of murine BM-residing VSELs because of the possibility of contamination by small CD45-negative erythroblasts.

Unfortunately, the second group [33] also did not avoid several major technical mistakes that could result both in VSEL loss/exclusion and dilution with extraneous objects. The reason for this was (i) expanding the gating for VSEL isolation to include extraneous objects (including $\operatorname{Lin}^{\mathrm{dim}}$ and CD45 $5^{\text {dim }}$ cells), resulting in VSEL dilution and enrichment in erythroblasts and (ii) relying on inexact Syto-16 staining as the main indicator of "VSEL candidates," which, in fact, are an incorrect, non-VSEL fraction [33]. Together, these approaches led to both VSEL dilution and loss and had a critical effect on the subsequent gene expression and functional analysis of these cells.

In contrast to murine VSELs, phenotypically corresponding human VSELs are isolated as a population of small $\mathrm{CD} 133^{+} \mathrm{Lin}^{-} \mathrm{CD} 45^{-}$cells. We reported that expression of CD133 antigen is, so far, the most important positive marker of human early-development VSELs [49]. However, human VSELs may also co-express CXCR4, CD34, and SSEA-4, the rarest population of $\mathrm{CD} 133^{+} \mathrm{Lin}^{-} \mathrm{CD} 45^{-}$cells is highly enriched for small Oct- $4^{+}$VSELs [8]. If a sorted population of human cells does not express CD133, it cannot be considered to be enriched for VSELs [31]. This can be observed in one report where [31] an FACS-sorted population of $\mathrm{CXCR} 4{ }^{+} \mathrm{Lin}^{-} \mathrm{CD} 45^{-}$cells that lacked expression of CD133 was mistakenly identified as UCB-derived VSELs [31]. Furthermore, this group not only replaced a reliable anti-CD133 antibody clone with one that is less effective for CD133 detection, but, in addition, "proved" the absence of a $\mathrm{CD} 133^{+} \mathrm{Lin}^{-} \mathrm{CD} 45^{-}$population of VSELs in UCB by employing histograms in their paper instead of dot plots [31]. It is well known that since VSELs are very rare, dot plot analysis is required to show the presence of these cells. 


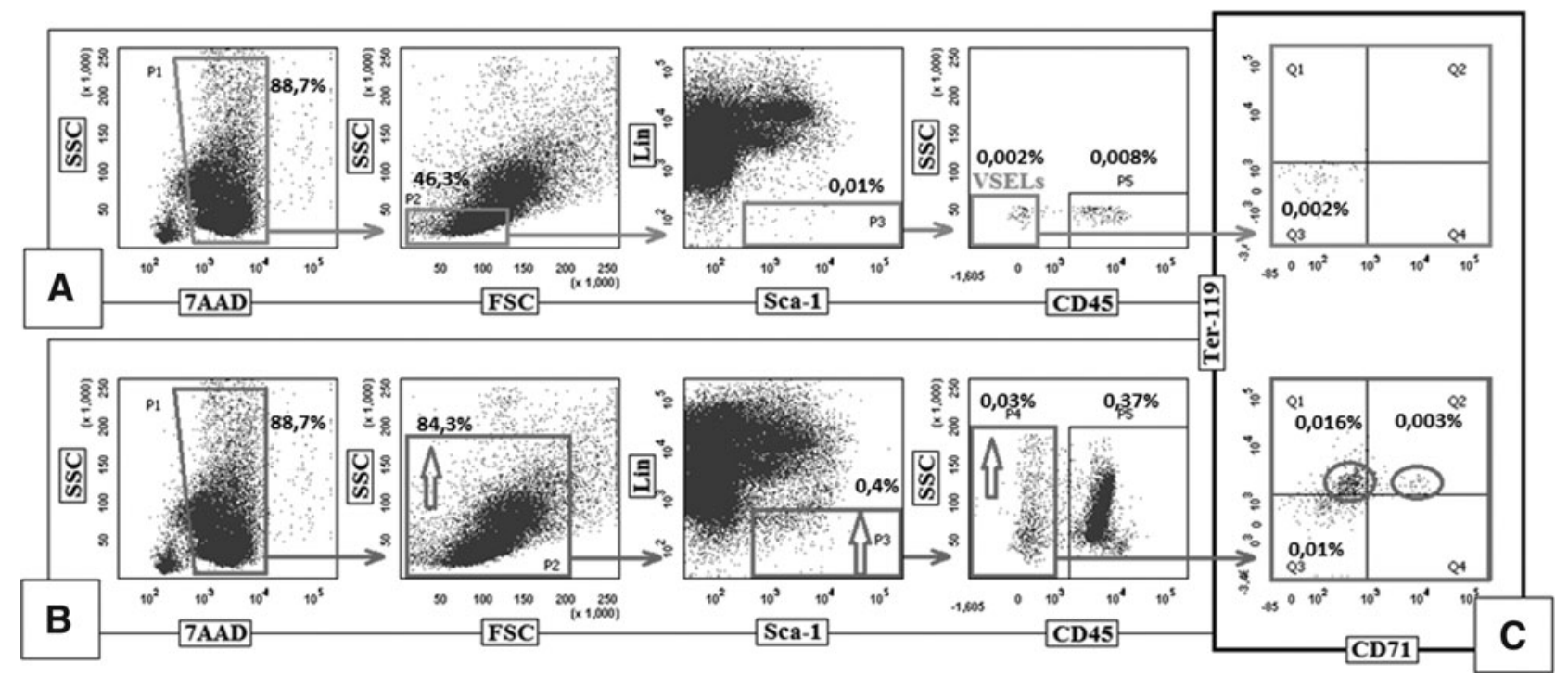

FIG. 1. Comparison of a correct and incorrect gating strategy for murine BM very small embryonic-like stem cells (VSELs). (A) The correct gating strategy to analyze or sort murine BM-derived VSELs by FACS. Cells were fixed and stained with 7AAD to show nucleated events in gate P1. Gate P2 includes small, agranular cells. Gate P3 includes Sca-1 ${ }^{+}$ $\mathrm{Lin}^{-}$cells, which are visualized on the next dot plot as CD45-negative (VSELs) and CD45-positive cells (HSCs). Expanding this gate into lineage ${ }^{\mathrm{dim}}$ population will result in contamination of VSELs by erythroblasts. Percentage shows the average content of each cellular subpopulation among total BM nucleated cells after fixation procedure and staining with 7ADD to gate for nucleated cells only. (B) An incorrect gating strategy (we followed the sorting procedure employed by Szade et al. [32]). As shown, this group employed extended regions P2, P3, and P4, (indicated by arrows) which resulted in enrichment of erythroblasts. (C) Expression of erythroblastic markers: CD71 and Ter-119 (markers of early-stage and more differentiated erythroblasts) in cells sorted by employing correct (A) and incorrect (B) sorting strategies. Cells enclosed by circles in the lower dot plot indicate an erythroblast population that contaminates the VSELs, which is not observed in cells sorted by the correct strategy (upper dot plot).

Figure 2 demonstrates an example of the analysis of UCBderived $\mathrm{CD}_{133}{ }^{+} \operatorname{lin}^{-} \mathrm{CD} 45^{-}$cells by histogram as was performed by this group [31] versus a dot plot, as they should be presented. Thus, based on histogram data, this group [31] isolated an incorrect population of cells for further analysis, and what is even more interesting, failed to realize that, in fact, on the original histogram curves in their paper, small "teeth" corresponding to rare VSELs are visible, and not displaying their data in a dot plot [31].

\section{VSELs Express Several PSCs Markers and Exhibit the In Vitro Criteria of PSCs But Do Not Complete Blastocyst Development and Do Not Grow Teratomas}

Several stringent in vitro and in vivo criteria for defining stem cells as PSCs have been proposed by embryologists who are working with embryonic stem cells (ESCs) isolated from embryos or induced PSCs (iPSCs), and we reviewed these criteria in our recent publications [50,51].

In brief, recent experimental data showed that murine BM VSELs fulfill all the in vitro criteria expected for PSCs. Specifically, they possess the primitive morphology of earlydevelopment cells (high nuclear/cytoplasmic ration, the presence of euchromatin in nuclei, and a few mitochondria) and express markers typical of PSCs (eg, Oct-4, Nanog, and $\operatorname{Rex}-1)$. More importantly, we recently demonstrated the presence of an open-type chromatin in the Oct-4 promoter in murine BM VSELs. Specifically, molecular analysis revealed its hypomethylation and association with transcription-permissive histones (indicated by a high $\mathrm{H} 3 \mathrm{Ac} /$ H3K9me2 ratio) [24]. Moreover, the promoter of another core transcription factor, Nanog, despite having a higher level of methylation in VSELs $(\sim 50 \%)$ than the Oct-4 promoter, is also transcriptionally active and has a high $\mathrm{H} 3 \mathrm{Ac} / \mathrm{H} 3 \mathrm{~K} 9 \mathrm{me} 2$ ratio that favors transcription [24]. Based on these results, we conclude that murine VSELs truly express both Oct-4 and Nanog [24]. With regard to the other in vitro criteria of pluripotency, murine VSELs also possess bivalent domains in promoters that encode developmentally important homeoboxcontaining transcription factors, such as Sox21, Nkx2.2, Dlx1, Lbx1h, Hlxb9, Pax5, and HoxA3 [26]. Furthermore, VSELs derived from female mice reactivate the X-chromosome [51]. Finally, we and other groups have succeeded in differentiating VSELs in vitro into cells of all three germ layers $[4,36,39,40,42,52]$.

Nevertheless, in contrast to pluripotent ESCs and iPSCs, murine VSELs do not complete blastocyst development and do not grow teratomas in immunodeficient mice [24,50]. This discrepancy between in vitro and in vivo pluripotency criteria can be explained by epigenetic changes in the expression of some paternally imprinted genes [24] that govern quiescence of these rare cells. Specifically, VSELs, similar to primordial germ cells (PGCs), erase imprinting in regulatory regions for paternally imprinted genes at the Igf2$H 19$ and RasGRF1 loci and increase imprinting at some regulatory regions for maternally imprinted genes such as $I g f 2 R$ and $K C N Q 1$. Thus, murine BM VSELs, by epigenetic modulation of imprinted genes (Igf2-H19, RasGRF1, and $I G F 2 R$ ) that play an important a role in IIS, remain resistant 


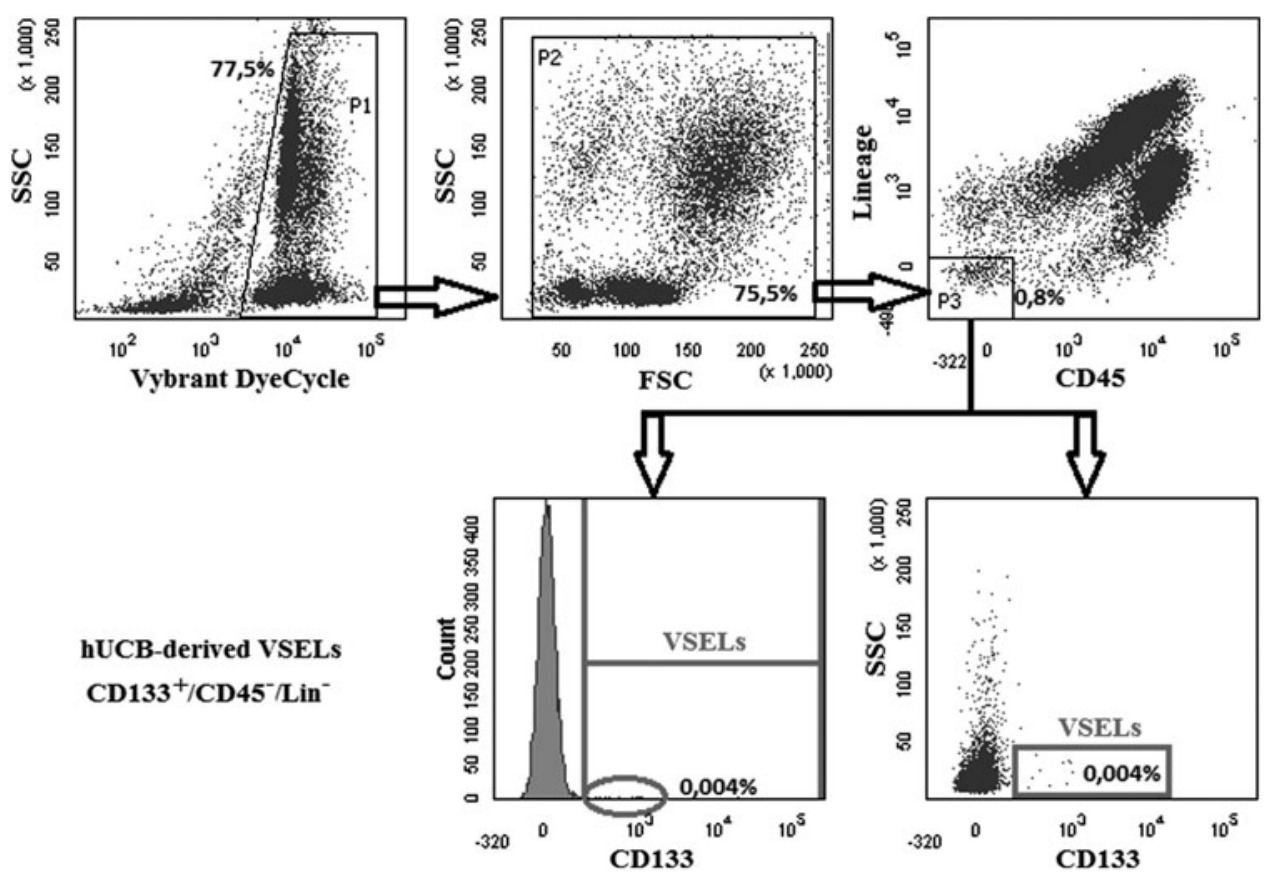

FIG. 2. FACS analysis of umbilical cord blood (UCB) $\mathrm{CD} 133^{+} \mathrm{Lin}^{-} \mathrm{CD} 45^{-}$VSELs. UCB VSELs are very rare cells, and their content varies, sometimes significantly, between UCB units. Upper panel-P1-shows DNA positive events shown in P2 as SSC versus FSC dot plot. P3-includes Lin $^{-}$CD45 ${ }^{-}$cells. These human UCB Lin ${ }^{-} \mathrm{CD}^{-} 5^{-}$cells were subsequently evaluated by FACS for the expression of CD133 antigen. The lower left panel illustrates an analysis for the presence of $\mathrm{CD}_{13} 3^{+}$cells in cells from $\mathrm{P} 1 / \mathrm{P} 2 / \mathrm{P} 3$ by employing a histogram, and the right panel is a visualization of these rare cells by dot plot. Danova-Alt et al. [31], in their recent studies, concluded that CD $133^{+} \mathrm{CD}_{4} 5^{-} \mathrm{Lin}^{-}$cells as well as $\mathrm{CD} 34^{+} \mathrm{CD} 45^{-} \mathrm{Lin}^{-}$cells do not exist in UCB. In fact, one of the reasons that these rare stem cell populations were overlooked by Danova-Alt and colleagues is they employed histograms instead of dot plot cytograms [31].

to stimulation by insulin, IGF-1, and IGF-2 and to additional modulation of expression of the KCNQ1 locus, which regulates expression of the cell cycle inhibitor p57Kip2. As a result of this resistance, VSELs remain in adult tissues as a population of highly quiescent cells [24], and, therefore, these epigenetic changes explain their lack of ex vivo expansion.

Considering the in vivo criteria of stem cell pluripotentiality, one has to consider that while all these in vivo criteria apply very well to ESCs and iPSCs [53,54], they are not always applicable for other pluripotent stem cells such as epiblast stem cells (EpiSCs) [55-58] or PGCs [59-61]. In particular, PGCs, by changes in expression of imprinted genes, remain quiescent, do not proliferate, do not complement blastocyst development, and do not form teratomas [62-65]. However, they may be converted by appropriate manipulation to embryonic germ cells (EGCs), but this requires appropriate changes in the expression of the imprinted genes mentioned earlier $[24,66]$. This well-known fact has also important practical implications. As previously reported, since murine BM VSELs express several markers of migrating PGCs and undergo similar (but not identical) epigenetic changes as PGCs in the expression of imprinted genes [24], it might be possible by manipulating the expression of imprinted genes to reprogram them to a proliferation-permissive state and expand them ex vivo for therapeutic purposes. This is one of the current challenges in our laboratory.

In Table 1, we have summarized the most important characteristics of murine and human VSELs.

\section{Why "Small Embryonic-Like" Stem Cells?}

The name "embryonic" has been proposed historically, based initially on the morphology of these cells and transmission electron microscope images that revealed a similar chromatin structure as the chromatin in ESCs [3,67]. Furthermore, molecular analysis of gene expression performed later revealed that VSELs express not only Oct-4, Nanog, and Rex-1 but, in addition, also several markers characteristic of EpiSCs and epiblast-derived migratory PGCs $[23,28]$. We are aware that the name "embryonic-like" may create some confusion, in particular, when size and morphology of VSELs are compared with that of established immortalized ESC lines. However, one should take into consideration that stem cells in the preimplantation blastocyst or epiblast are very small and, in addition, we have to consider that quiescent cells residing in adult tissues have reduced cytoplasm and a high nuclear/cytoplasmic ratio.

In fact, several investigators have described populations of very small stem cells in adult murine [15,34-37,45,68], and most likely, some of these cell populations that possess broader differentiation potential across germ layers could be related to the VSELs (Table 2).

\section{The Biological Function of VSELs in BM and Other Adult Tissues}

We and others postulate that in BM, VSELs are a dormant population of stem cells which serve as precursors for longterm repopulating HSCs (LT-HSCs) [50,69,70] and MSCs 
Table 1. The Most Important Identification Criteria That Are Attributable to BM-Purified Murine VSELS AND HUMAN UCB-ISOLATED VSELS

Source
of VSELs Characteristics

Murine Enriched in population of cells that are slightly
VSEL smaller than red blood cells.

Primitive morphology, large nuclei contain euchromatin, high nuclear/cytoplasmic ratio.

Quiescent cells due to epigenetic changes in expression of some genes regulated by paternal imprinting (eg, Igf2-H19, RasGrf1, IGF2R, and p57Kip2). It also explains that they neither form teratomas nor complement blastocyst development.

Purified VSELs are enriched for cells that express some markers characteristic for pluripotent stem cells (Oct-4, Nanog, SSEA-1, and presence of bivalent domains), epiblast and germ line cell markers.

Number of VSELs decreases with the age and correlates with life span in experimental animals.

In appropriate experimental models murine VSELs differentiate into cells from all three germ layers, including germ line.

Highly resistant to stress, irradiation and cytostatics.

Human Enriched in a population of cells that are VSELs ${ }^{b}$ slightly smaller than red blood cells.

Primitive morphology, large nuclei contain euchromatin, high nuclear/cytoplasmic ratio.

Purified human UCB-VSELs are enriched for cells that express some markers characteristic for pluripotent stem cells (eg, Oct-4, Nanog, and SSEA-4) and some epiblast and primordial germ cell markers.

Do not form teratomas in experimental animals

Quiescent cells due to epigenetic changes in expression of some genes regulated by paternal imprinting (eg, Igf2-H19).

In appropriate experimental models, human VSELs differentiate into hematopoietic cells, mesenchymal stem cells, and neural cells. Moreover, VSELs isolated from human gonads also differentiate into germ line cells.

${ }^{\mathrm{a}}$ The best characterized so far at molecular level are murine VSELs purified from BM. More work is needed to compare VSELs isolated from other tissues with BM-purified ones.

${ }^{\mathrm{b}}$ Recent data reported on VSELs-like cells isolated from human ovaries indicate their molecular similarity to murine BM-purified VSELs [14,15,18,68,117,118].

VSEL, very small embryonic-like stem cells; UCB, umbilical cord blood; BM, bone marrow.

[40,41]. By contrast, VSELs residing in the gonads give rise to gametes $[15,68,71]$. However, more studies are required to see whether VSELs in other organs play a similar role as precursors for monopotent TCSCs. Evidence has accumulated that VSELs are activated and mobilized into PB during tissue or organ injuries in murine and human models of heart infarct [10,44,72], stroke [11], skin burns [13], colitis ulcerosa [12], and tumor expansion [46] and in several of these pathologic situations, the number of VSELs circulating in peripheral blood may be of some prognostic value.
Table 2. Examples of Selected Reports FROM OTHER INDEPENDENT GROUPS ON SMALL Stem Cells That Are Attributable to VSELS

Cells name as originally described in the literature References

ELH cells-Very small cells $\sim 5 \mu \mathrm{m}$ in diameter isolated by elutriation and [34,35,119] FACS sorting or by elutriation $(\mathrm{E})$, lineage depletion (L), and recovered after homing $(\mathrm{H})$ to $\mathrm{BM}$. Give rise to long-term reconstituting hematopoietic cells (LT-HSCs) and epithelial cells.

Small nonhematopoietic Sca- $1^{+}$ $\mathrm{Lin}^{-} \mathrm{CD}^{-} 5^{-}$cells-Isolated by FACS from murine $\mathrm{BM}$ give rise to type II pneumocytes, producing surfactant in lung alveolar epithelium. Recently, these cells have been confirmed to be VSELs.

Pluripotent $\mathrm{CD}^{2} 5^{-} \mathrm{Sca}-\mathrm{I}^{+} \mathrm{c}$-kit cellsIsolated by FACS from murine BM, muscles, and intestinal epithelium that are able to differentiate into cells from all three germ layers.

Spore-like stem-cells-Very small cells, $\sim 5 \mu \mathrm{m}$ in diameter, isolated from various murine tissues, resistant to freeze/thawing, expressing Oct-4, and showing broad differentiation. The isolation procedure of these small cells not revealed in original paper.

Rat embryonic-like stem cells (ELSCs) Very small cells, $\sim 5 \mu \mathrm{m}$ in diameter, isolated by FACS from rat bone marrow as SSEA- ${ }^{+}$Lin $^{-} \mathrm{CD} 45^{-}$ population. These cells as reported express Oct-4 and are endowed with in vitro and in vivo cardiomyogenic and endothelial potential.

Ovarian and testicular VSELs-Small Oct $-4^{+}$SSEA $^{+}$cells isolated by FACS from ovarian surface epithelium (OSE) from mice $\left(\right.$ SSEA $\left.-1^{+}\right)$and humans (SSEA- $\left.4^{+}\right)-$ precursors of female gametes. Human OSE-derived VSELs were characterized extensively by gene array for mRNA expression. Small Oct- $4^{+}$SSEA $^{+}$cells were also identified in murine and human testes as precursors of male gametes.

Embryonic-like stem-cells from UCBSmall CD45 ${ }^{-}, \mathrm{CD}_{3}{ }^{-}, \mathrm{CD}^{-}$, CD235a ${ }^{-}$pluripotent stem-cells ( $\sim 3 \mu \mathrm{m}$ in diameter) co-expressing embryonic stem-cell markers, including Oct-4 and Sox2, and able to differentiate into neuronal cells.

Human UCB-derived VSELs - Small Oct- $4^{+}$, SSEA $-4^{+}$, Nanog $^{+}$, Sox $2^{+}$, Rex $-1^{+}$, and Tert ${ }^{+}$cells. (continued) 
TABle 2. (CONTINUEd)

\begin{tabular}{|c|c|}
\hline $\begin{array}{l}\text { Cells name as originally described } \\
\text { in the literature }\end{array}$ & References \\
\hline $\begin{array}{l}\text { Human PB-derived VSELs-Oct-4 } \\
\text { very small cells isolated by FACS. In } \\
\text { one of the reports SSEA-4 } 4^{+} \text {CD } 133^{+} \\
\text {CXCR } 4^{+} \text {Lin }{ }^{-} \text {and CD } 45^{-} \text {VSELs } \\
\text { from human PB formed in } \\
\text { immunodeficient mice vascularized } \\
\text { bone fragments. }\end{array}$ & {$[9,41]$} \\
\hline $\begin{array}{l}\text { Omnicytes }- \text { Small Oct- } 4^{+} \text {stem-cells } \\
\text { identified in UCB, able to establish } \\
\text { fetal-maternal chimerism. }\end{array}$ & [38] \\
\hline $\begin{array}{l}\text { UCB-derived nonhematopoietic CD } 34^{-} \\
\text {Oct- } 3 / 4^{+} \text {, Sox } 2^{+}, \text {Rex- } 1^{+} \text {cells-that } \\
\text { are able to differentiate into neural } \\
\text { lineage (neurons, astrocytes, } \\
\text { oligodendrocytes). }\end{array}$ & [120] \\
\hline
\end{tabular}

The number of VSELs in adult murine tissues reportedly decreases with age [73-75], and the number of these cells also correlates with lifespan in mice. Mice that live longer (eg, Laron and Ames dwarfs) maintain higher numbers of these cells in BM [73]. Preliminary not published data also indicate a positive effect of physical activity and calorie restriction in maintaining a high number of VSELs in adult murine tissues.

Based on this evidence, VSELs could be a back-up population of dormant stem cells in adult tissues that plays, on the one hand, an important role in organ regeneration during tissue injuries, and on the other hand, is involved in rejuvenation of the tissues. Since the number of these cells decreases with the age [73-75], this could help explain both the impaired regeneration and tissue rejuvenation observed in older individuals.

\section{What Is the Rationale for Why PSCs/MPSCs Reside in Adult Tissues?}

A decade ago, the concept of stem cell plasticity was proposed, based on the assumption that adult monopotent TCSCs (eg, HSCs) may trans-dedifferentiate into cells from other germ layers (eg, neural cells) [76-80]. This concept is currently rejected by a majority of the scientific community, and alternative explanations for the "phenomenon of stem cell plasticity" have been proposed, such as cell fusion [81-83] or the presence of heterogeneous populations of stem cells, for example, in BM, UCB, or $\mathrm{mPB}$, including some rare stem cells endowed with broader differentiation potential $[1,5,6,36,47,84,85]$. Moreover, in parallel, cumulative evidence from several laboratories shows that in the adult tissues may reside cells which express some early development embryonic markers [5,6,30,86-95], and some of these cells may even possess germ line potential [96-103]. Some of these intriguing cells are listed in Table 3 . It is important to emphasize that murine BM-purified VSELs are enriched as mentioned earlier in cells which express several markers characteristic for migrating PGCs [23].

In support of the presence of early development stem cells in postnatal life, several types of putative PSCs or MPSCs have been described and isolated, primarily from hematopoietic tissues and that are able to give rise to cells from
Table 3. Selected Reports from Other Groups on Stem Cells in Adult Nongonadal Tissues

That Possess Germ Line Potential and/or

Express Embryonic Stem Cell Markers (EG, OCT-4, SSEA, AND MvH)

Cells name as originally described in the References literature

Stem cells with germ line potential from

newborn mouse skin-Oct-4 ${ }^{+}$cells isolated

by FACS from Oct-4-GFP mice that are able

to give rise in vitro and in vivo to early oocytes.

Porcine multipotent stem/stromal cells-

Oct- $3 / 4^{+}, \mathrm{Nanog}^{+}$, Sox $2^{+}$cells isolated

from porcine skin and adipose tissue able to

differentiate into oocyte like cells.

SSEA $-1^{+}$murine BM cells-Isolated from

murine BM by anti-SSEA-1

immunomagnetic beads. In the presence of

BMP4 (bone morphogenic factor-4), they

differentiate into Oct- $4^{+}$Stella $^{+} \mathrm{Mvh}^{+}$and

into gamete precursors.

$B M$-derived putative germ cells-

Oct-4 + Mvh + Dazl + Stella + cells present in

BM that may affect recurrence of oogenesis in mice sterilized by chemotherapy.

BM-derived male germ cells-Oct- $4^{+}, \mathrm{Mvh}^{+}$, Stella $^{+}$cells isolated as Stra8-GFP cells

from BM from Stra8-GFP transgenic mice.

These cells express several molecular

markers of spermatogonial stem cells and spermatogonia.

$B M$-derived precursors of male germ cells$\mathrm{GFP}^{+}$transgenic chicken Oct- ${ }^{+}$

SSEA-1/3/4 ${ }^{+}$BM cells after injection into testes give rise to functional sperm.

more than one germ layer [36,87,104-109]. These cells were isolated by employing various strategies, such as ex vivo expansion of partially purified immunomagnetic- or FACSbased sorted cells [35,36,39,45,87,104,107,108]. Nevertheless, in most of the expansion cultures, those rare cells that were able to initiate expansions and cross germ-layer commitment were not characterized at the single-cell level $[78,87,105,106,108]$, and in most of these cases, the phenotype of the putative stem cell with PSC/MPSC properties was described " post factum," after phenotyping clones of already differentiated, in vitro-expanded cells [87,104,108,110]. Nevertheless, many of the investigators would agree that if early-development stem cells endowed with broader differentiation potential reside in adult tissues, they are probably closely related and exist at different levels of tissue specification. Most likely, they represent overlapping populations of early-development stem cells that, depending on isolation strategy, ex vivo expansion protocol, and markers employed for their identification, have been given different names [87,104,105,107,108,110-112]. Figure 3 shows a hypothetical relationship to other populations of multi/pluripotent stem cells described in adult BM, PB, and UCB such as, for example, Multipotent Adult Stem Cells (MASC) [104], Multilineage-differentiating stress-enduring cells (Muse) [110,111], MSCs [112], Multipotent Adult Progenitor Cells [106], Unrestricted Somatic Stem Cells [107], Marrow- 


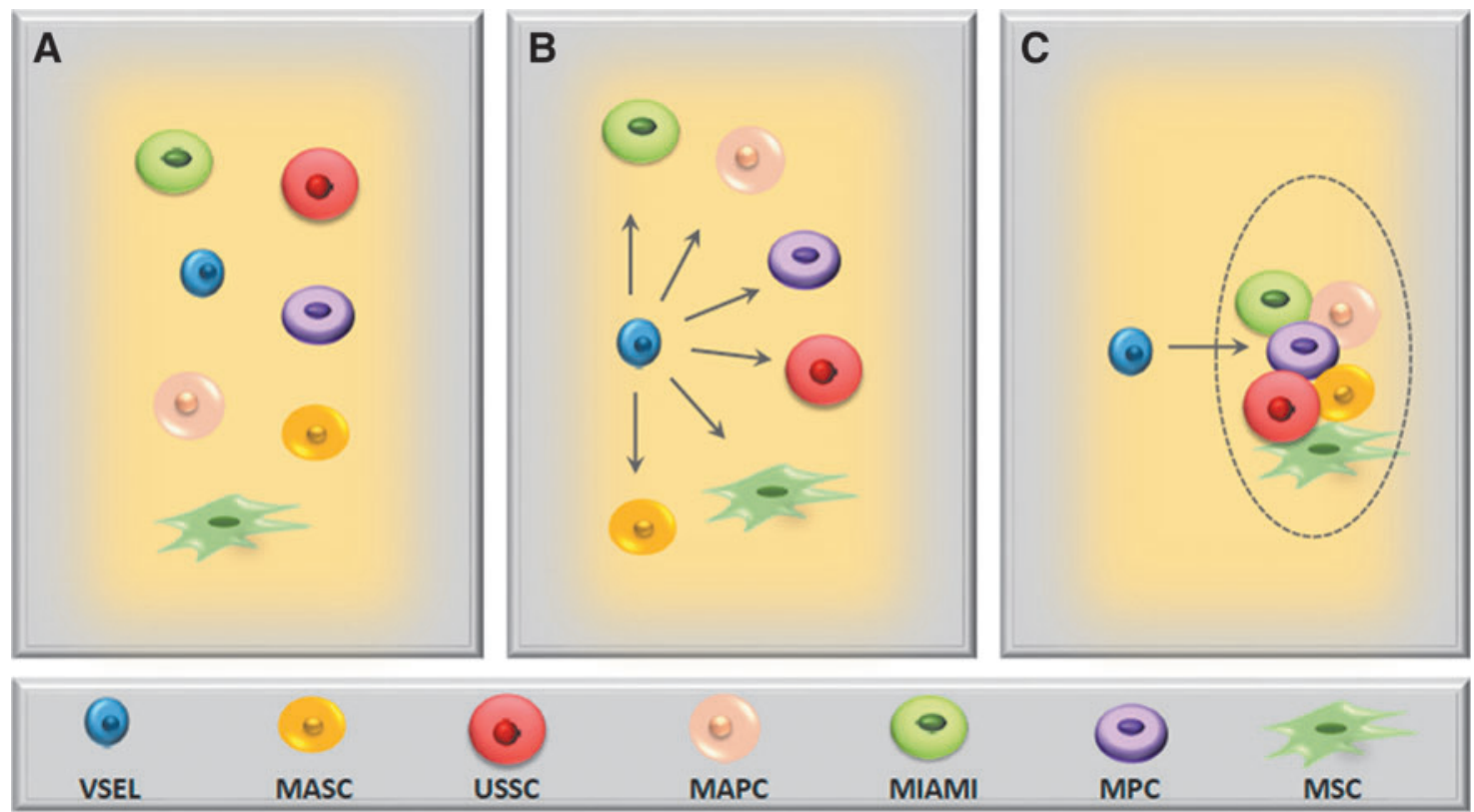

FIG. 3. Hypothetical relation of VSELs to other multi/pluripotent stem cells identified in adult bone marrow (BM), peripheral blood (PB), and UCB. (A) VSELs and other multi/pluripotent stem cells identified in hematopoietic tissues are independent populations of stem cells. (B) VSELs are the most primitive small dormant stem cells that on proper activation give rise to expanding other larger multi/pluripotent stem cells. (C) VSELs are the most primitive small dormant stem cells that on proper activation give rise to other larger multi/pluripotent overlapping stem cell populations. We hypothesize that it is the most likely scenario.

Isolated Adult Multilineage-Inducible Cells [108], and Multipotent Progenitor Cells [87,104].

Overall, the presence of PSCs/MPSCs in adult tissues can be explained by the possibility that early, during embryogenesis, not all of the earliest-development stem cells disappear from the embryo after giving rise to TCSCs, but some may survive in developing organs as "a dormant backup population of more primitive stem cells" [113]. These cells could give rise to monopotent TCSCs and, thus, be involved in tissue/organ rejuvenation and in organ regeneration after organ injury. In support of this notion, evidence has accumulated that adult murine tissues, in fact, contain, in addition to rapidly proliferating stem cells, a back-up population of more primitive dormant stem cells $[3,4]$. We have proposed as mentioned earlier that these mostprimitive dormant stem cells are kept quiescent in adult tissues by changes in the expression of imprinted genes which mostly regulate insulin/insulin like growth factor-1 and -2 signaling (IIS) [24,66]. Interestingly, our proposal that the most-primitive stem cells in adult tissues which give rise to BM LT-HSCs [42,47] follow this mechanism has been recently somehow confirmed by another group [114]. Thus, we envision that VSELs, or stem cells very closely related to them, could fulfill the criteria for such dormant stem cells in adult tissues [113]. This, however, requires further experimental evidence, in particular for the most-primitive stem cells residing in other extra-hematopoietic tissues.

\section{Future Directions}

Despite significant progress in the field, there are still many problems with VSELs that should be solved. First, most of the data has been generated so far in murine
BM-derived VSELs. We do not know whether phenotypically similar VSELs residing in other murine organs are regulated in the same way. Second, we are aware that we may be purifying a collection of small cells which are at different levels of tissue specification and development. Third, we also do not know whether human VSELs have a same molecular signature as their murine counterparts. Finally, as mentioned earlier, expansion in vitro is still a problem for both murine and human VSELs. We believe that the most important reason for these obvious obstacles is epigenetic modification of some imprinted genes in these cells [24] and unfortunately, our in vitro models which we applied so far did not provide optimal signals and microenvironment to reverse this phenomenon. Therefore, we need to explore the possibility that modification of imprinted genes in VSELs, as reported for PGCs [62-64], could help expand these cells. Another strategy would be to find a proper scaffold or supportive microenvironment that will force expansion and differentiation of VSELs, similarly as has been recently reported for other types of stem cells $[115,116]$.

We expect that the next few years will bring answers about the developmental origin and biological role of this distinct and intriguing population of stem cells residing in adult tissues. We should also seriously consider a new hierarchy for the stem cell compartment not only in adult BM but also in other tissues and try to investigate the mutual relationship between VSELs and PSCs and MPSCs described by different investigators in adult organs [5,15,35,36,41,85,88,109].

Finally, we ask the scientific community to follow our well-described isolation protocols [19] and directly contact our group if there are problems with gating and sorting of these very rare cells. This will avoid confusion in the field 
and situations in which cells are identified as VSELs but lack a true VSEL phenotype [31-33]. While this paper was prepared for print two recent reports confirmed presence of VSELs in adult human and murine tissues [121, 122].

\section{Acknowledgments}

This study was supported by UE structural funds, the Innovative Economy Operational Program POIG.01.01.02-00109/09 grant, NIH grants 2R01 DK074720 and R01HL112788, and the Stella and Henry Endowment to MZR.

\section{Author Disclosure Statement}

The University of Louisville is the owner of patents on VSELs and some areas of VSEL technology are licensed to Neostem, Inc., New York. None of the authors have any stock in Neostem or any other biotechnological stem cell company.

\section{References}

1. Kucia M, R Reca, FR Campbell, E Zuba-Surma, M Majka, J Ratajczak and MZ Ratajczak. (2006). A population of very small embryonic-like (VSEL) CXCR4(+) SSEA-1 $(+)$ Oct- $4+$ stem cells identified in adult bone marrow. Leukemia 20:857-869.

2. Kucia M, W Wu and MZ Ratajczak. (2007). Bone marrow-derived very small embryonic-like stem cells: their developmental origin and biological significance. Dev Dyn 236:3309-3320.

3. Kucia M, M Wysoczynski, J Ratajczak and MZ Ratajczak. (2008). Identification of very small embryonic like (VSEL) stem cells in bone marrow. Cell Tissue Res 331: $125-134$.

4. Zuba-Surma EK, M Kucia, W Wu, I Klich, JW Lillard, Jr., J Ratajczak and MZ Ratajczak. (2008). Very small embryonic-like stem cells are present in adult murine organs: ImageStream-based morphological analysis and distribution studies. Cytometry A 73A:1116-1127.

5. McGuckin CP, N Forraz, MO Baradez, S Navran, J Zhao, R Urban, R Tilton and L Denner. (2005). Production of stem cells with embryonic characteristics from human umbilical cord blood. Cell Prolif 38:245-255.

6. McGuckin C, M Jurga, H Ali, M Strbad and N Forraz. (2008). Culture of embryonic-like stem cells from human umbilical cord blood and onward differentiation to neural cells in vitro. Nat Protoc 3:1046-1055.

7. Bhartiya D, A Shaikh, P Nagvenkar, S Kasiviswanathan, $P$ Pethe, H Pawani, S Mohanty, SG Rao, K Zaveri and I Hinduja. (2012). Very small embryonic-like stem cells with maximum regenerative potential get discarded during cord blood banking and bone marrow processing for autologous stem cell therapy. Stem Cells Dev 21:1-6.

8. Kucia M, M Halasa, M Wysoczynski, M BaskiewiczMasiuk, S Moldenhawer, E Zuba-Surma, R Czajka, W Wojakowski, B Machalinski and MZ Ratajczak. (2007). Morphological and molecular characterization of novel population of CXCR4+ SSEA-4+ Oct-4+ very small embryonic-like cells purified from human cord blood: preliminary report. Leukemia 21:297303.

9. Sovalat H, M Scrofani, A Eidenschenk, S Pasquet, V Rimelen and P Henon. (2011). Identification and isolation from either adult human bone marrow or G-CSF-mobilized peripheral blood of CD34(+)/CD133(+)/CXCR4(+)/Lin $(-)$ CD45(-) cells, featuring morphological, molecular, and phenotypic characteristics of very small embryonic-like (VSEL) stem cells. Exp Hematol 39:495-505.

10. Wojakowski W, M Tendera, M Kucia, E Zuba-Surma, E Paczkowska, J Ciosek, M Halasa, M Krol, M Kazmierski, et al. (2009). Mobilization of bone marrow-derived Oct$4+$ SSEA-4 + very small embryonic-like stem cells in patients with acute myocardial infarction. J Am Coll Cardiol 53:1-9.

11. Paczkowska E, M Kucia, D Koziarska, M Halasa, K Safranow, M Masiuk, A Karbicka, M Nowik, P Nowacki, MZ Ratajczak and B Machalinski. (2009). Clinical evidence that very small embryonic-like stem cells are mobilized into peripheral blood in patients after stroke. Stroke 40:1237-1244.

12. Marlicz W, E Zuba-Surma, M Kucia, W Blogowski, T Starzynska and MZ Ratajczak. (2012). Various types of stem cells, including a population of very small embryonic-like stem cells, are mobilized into peripheral blood in patients with Crohn's disease. Inflamm Bowel Dis 18:1711-1722.

13. Drukala J, E Paczkowska, M Kucia, E Mlynska, A Krajewski, B Machalinski, Z Madeja and MZ Ratajczak. (2012). Stem cells, including a population of very small embryonic-like stem cells, are mobilized into peripheral blood in patients after skin burn injury. Stem Cell Rev 8:184-194.

14. Virant-Klun I, N Zech, P Rozman, A Vogler, B Cvjeticanin, $\mathrm{P}$ Klemenc, E Malicev and $\mathrm{H}$ Meden-Vrtovec. (2008). Putative stem cells with an embryonic character isolated from the ovarian surface epithelium of women with no naturally present follicles and oocytes. Differentiation 76:843-856.

15. Parte S, D Bhartiya, J Telang, V Daithankar, V Salvi, K Zaveri and I Hinduja. (2011). Detection, characterization, and spontaneous differentiation in vitro of very small embryonic-like putative stem cells in adult mammalian ovary. Stem Cells Dev 20:1451-1464.

16. Ratajczak J, M Kucia, K Mierzejewska, W Marlicz, Z Pietrzkowski, W Wojakowski, NJ Greco, M Tendera and MZ Ratajczak. (2013). Paracrine proangiopoietic effects of human umbilical cord blood-derived purified CD133+ cells-implications for stem cell therapies in regenerative medicine. Stem Cells Dev 22:422-430.

17. Zuba-Surma EK, I Klich, N Greco, MJ Laughlin, J Ratajczak and MZ Ratajczak. (2010). Optimization of isolation and further characterization of umbilical cord blood-derived very small embryonic/epiblast-like stem cells (VSELs). Eur J Haematol 84:34-46.

18. Virant-Klun I, T Skutella, M Hren, K Gruden, B Cvjeticanin, A Vogler and J Sinkovec. (2013). Isolation of small SSEA-4-positive putative stem cells from the ovarian surface epithelium of adult human ovaries by two different methods. Biomed Res Int 2013:690415.

19. Zuba-Surma EK and MZ Ratajczak. (2010). Overview of very small embryonic-like stem cells (VSELs) and methodology of their identification and isolation by flow cytometric methods. Curr Protoc Cytom Chapter 9: Unit9 29.

20. Halasa M, M Baskiewicz-Masiuk, E Dabkowska and B Machalinski. (2008). An efficient two-step method to purify very small embryonic-like (VSEL) stem cells from 
umbilical cord blood (UCB). Folia Histochem Cytobiol 46:239-243.

21. Ratajczak MZ, E Zuba-Surma, W Wojakowski, M Suszynska, K Mierzejewska, R Liu, J Ratajczak, D MyungShin and M Kucia. (2013). Very Small Embryonic Like Stem Cells (VSELs) represent a real challenge in stem cell biology. Recent pros and cons in the midst of a lively debate. Leukemia [Epub ahead of print]; DOI:10.1038/ leu.2013.255.

22. Ratajczak MZ, M Kucia, J Ratajczak and EK ZubaSurma. (2009). A multi-instrumental approach to identify and purify very small embryonic like stem cells (VSELs) from adult tissues. Micron 40:386-393.

23. Shin DM, R Liu, I Klich, W Wu, J Ratajczak, M Kucia and MZ Ratajczak. (2010). Molecular signature of adult bone marrow-purified very small embryonic-like stem cells supports their developmental epiblast/germ line origin. Leukemia 24:1450-1461.

24. Shin DM, EK Zuba-Surma, W Wu, J Ratajczak, M Wysoczynski, MZ Ratajczak and M Kucia. (2009). Novel epigenetic mechanisms that control pluripotency and quiescence of adult bone marrow-derived Oct4(+) very small embryonic-like stem cells. Leukemia 23:2042-2051.

25. Mierzejewska K, J Heo, JW Kang, H Kang, J Ratajczak, MZ Ratajczak, M Kucia and DM Shin. (2013). Genomewide analysis of murine bone marrowderived very small embryonic-like stem cells reveals that mitogenic growth factor signaling pathways play a crucial role in the quiescence and ageing of these cells. Int $\mathrm{J}$ Mol Med 32:281-290.

26. Shin DM, R Liu, W Wu, SJ Waigel, W Zacharias, MZ Ratajczak and M Kucia. (2012). Global gene expression analysis of very small embryonic-like stem cells reveals that the Ezh2-dependent bivalent domain mechanism contributes to their pluripotent state. Stem Cells Dev 21:1639-1652.

27. Zuba-Surma EK and MZ Ratajczak. (2011). Analytical capabilities of the ImageStream cytometer. Methods Cell Biol 102:207-230.

28. Shin DM, R Liu, I Klich, J Ratajczak, M Kucia and MZ Ratajczak. (2010). Molecular characterization of isolated from murine adult tissues very small embryonic/epiblast like stem cells (VSELs). Mol Cells 29:533-538.

29. Virant-Klun I, T Skutella, M Kubista, A Vogler, J Sinkovec and H Meden-Vrtovec. (2013). Expression of pluripotency and oocyte-related genes in single putative stem cells from human adult ovarian surface epithelium cultured in vitro in the presence of follicular fluid. Biomed Res Int 2013:861460.

30. Virant-Klun I, M Stimpfel, B Cvjeticanin, E VrtacnikBokal and T Skutella. (2013). Small SSEA-4-positive cells from human ovarian cell cultures: related to embryonic stem cells and germinal lineage? J Ovarian Res $6: 24$

31. Danova-Alt R, A Heider, D Egger, M Cross and R Alt. (2012). Very small embryonic-like stem cells purified from umbilical cord blood lack stem cell characteristics. PLoS One 7:e34899.

32. Szade K, K Bukowska-Strakova, WN Nowak, A Szade, N Kachamakova-Trojanowska, M Zukowska, A Jozkowicz and J Dulak. (2013). Murine bone marrow Lin(-)Sca (-)1(+)CD45(-) very small embryonic-like (VSEL) cells are heterogeneous population lacking Oct-4A expression. PLoS One 8:e63329.
33. Miyanishi M, Y Mori, J Seita, JY Chen, S Karten, CK Chan, H Nakauchi and IL Weissman. (2013). Do pluripotent stem cells exist in adult mice as very small embryonic stem cells? Stem Cell Rep 1:198-208.

34. Krause DS, ND Theise, MI Collector, O Henegariu, S Hwang, R Gardner, S Neutzel and SJ Sharkis. (2001). Multi-organ, multi-lineage engraftment by a single bone marrow-derived stem cell. Cell 105:369-377.

35. Jones RJ, MI Collector, JP Barber, MS Vala, MJ Fackler, WS May, CA Griffin, AL Hawkins, BA Zehnbauer, et al. (1996). Characterization of mouse lymphohematopoietic stem cells lacking spleen colony-forming activity. Blood 88:487-491.

36. Howell JC, WH Lee, P Morrison, J Zhong, MC Yoder and EF Srour. (2003). Pluripotent stem cells identified in multiple murine tissues. Ann NY Acad Sci 996:158-173.

37. Vacanti MP, A Roy, J Cortiella, L Bonassar and CA Vacanti. (2001). Identification and initial characterization of spore-like cells in adult mammals. J Cell Biochem 80:455-460.

38. Mikhail MA, H M'Hamdi, J Welsh, N Levicar, SB Marley, JP Nicholls, NA Habib, LS Louis, NM Fisk and MY Gordon. (2008). High frequency of fetal cells within a primitive stem cell population in maternal blood. Hum Reprod 23:928-933.

39. Kassmer SH, H Jin, PX Zhang, EM Bruscia, K Heydari, JH Lee, CF Kim and DS Krause. (2013). Very small embryonic-like stem cells from the murine bone marrow differentiate into epithelial cells of the lung. Stem Cells. [Epub ahead of print]; DOI: 10.1002/stem.1413.

40. Taichman RS, Z Wang, Y Shiozawa, Y Jung, J Song, A Balduino, J Wang, LR Patel, AM Havens, et al. (2010). Prospective identification and skeletal localization of cells capable of multilineage differentiation in vivo. Stem Cells Dev 19:1557-1570.

41. Havens AM, Y Shiozawa, Y Jung, H Sun, J Wang, S McGee, A Mishra, LS Taichman, T Danciu, et al. (2013). Human very small embryonic-like cells generate skeletal structures, in vivo. Stem Cells Dev 22:622-630.

42. Ratajczak J, M Wysoczynski, E Zuba-Surma, W Wan, M Kucia, MC Yoder and MZ Ratajczak. (2011). Adult murine bone marrow-derived very small embryonic-like stem cells differentiate into the hematopoietic lineage after coculture over OP9 stromal cells. Exp Hematol 39: 225-237.

43. Dawn B, S Tiwari, MJ Kucia, EK Zuba-Surma, Y Guo, SK Sanganalmath, A Abdel-Latif, G Hunt, RJ Vincent, et al. (2008). Transplantation of bone marrow-derived very small embryonic-like stem cells attenuates left ventricular dysfunction and remodeling after myocardial infarction. Stem Cells 26:1646-1655.

44. Zuba-Surma EK, Y Guo, H Taher, SK Sanganalmath, G Hunt, RJ Vincent, M Kucia, A Abdel-Latif, XL Tang, et al. (2011). Transplantation of expanded bone marrowderived very small embryonic-like stem cells (VSELSCs) improves left ventricular function and remodelling after myocardial infarction. J Cell Mol Med 15:13191328.

45. Wu JH, HJ Wang, YZ Tan and ZH Li. (2012). Characterization of rat very small embryonic-like stem cells and cardiac repair after cell transplantation for myocardial infarction. Stem Cells Dev 21:1367-1379.

46. Jung Y, JK Kim, Y Shiozawa, J Wang, A Mishra, J Joseph, JE Berry, S McGee, E Lee, et al. (2013). 
Recruitment of mesenchymal stem cells into prostate tumours promotes metastasis. Nat Commun 4:1795.

47. Ratajczak J, E Zuba-Surma, I Klich, R Liu, M Wysoczynski, N Greco, M Kucia, MJ Laughlin and MZ Ratajczak. (2011). Hematopoietic differentiation of umbilical cord blood-derived very small embryonic/epiblast-like stem cells. Leukemia 25:1278-1285.

48. Liu R, I Klich, J Ratajczak, MZ Ratajczak and EK ZubaSurma. (2009). Erythrocyte-derived microvesicles may transfer phosphatidylserine to the surface of nucleated cells and falsely "mark" them as apoptotic. Eur J Haematol 83:220-229.

49. Ratajczak MZ, K Mierzejewska, J Ratajczak and M Kucia. (2013). CD133 Expression strongly correlates with the phenotype of very small embryonic-/epiblast-like stem cells. Adv Exp Med Biol 777:125-141.

50. Ratajczak MZ, DM Shin, R Liu, K Mierzejewska, J Ratajczak, M Kucia and EK Zuba-Surma. (2012). Very small embryonic/epiblast-like stem cells (VSELs) and their potential role in aging and organ rejuvenation-an update and comparison to other primitive small stem cells isolated from adult tissues. Aging (Albany NY) 4:235-246.

51. Ratajczak MZ, R Liu, J Ratajczak, M Kucia and DM Shin. (2011). The role of pluripotent embryonic-like stem cells residing in adult tissues in regeneration and longevity. Differentiation 81:153-161.

52. Kassmer SH, EM Bruscia, PX Zhang and DS Krause. (2012). Nonhematopoietic cells are the primary source of bone marrow-derived lung epithelial cells. Stem Cells 30:491-499.

53. Muller FJ, J Goldmann, P Loser and JF Loring. (2010). A call to standardize teratoma assays used to define human pluripotent cell lines. Cell Stem Cell 6:412-414.

54. Smith KP, MX Luong and GS Stein. (2009). Pluripotency: toward a gold standard for human ES and iPS cells. J Cell Physiol 220:21-29.

55. Xue K, JH Ng and HH Ng. (2011). Mapping the networks for pluripotency. Philos Trans R Soc Lond B Biol Sci 366:2238-2246.

56. Bernemann C, B Greber, K Ko, J Sterneckert, DW Han, MJ Arauzo-Bravo and HR Scholer. (2011). Distinct developmental ground states of epiblast stem cell lines determine different pluripotency features. Stem Cells 29: 1496-1503.

57. Hayashi K and MA Surani. (2009). Self-renewing epiblast stem cells exhibit continual delineation of germ cells with epigenetic reprogramming in vitro. Development 136: 3549-3556.

58. Gillich A, S Bao, N Grabole, K Hayashi, MW Trotter, V Pasque, E Magnusdottir and MA Surani. (2012). Epiblast stem cell-based system reveals reprogramming synergy of germline factors. Cell Stem Cell 10:425-439.

59. Leitch HG, J Nichols, P Humphreys, C Mulas, G Martello, C Lee, K Jones, MA Surani and A Smith. (2013). Rebuilding pluripotency from primordial germ cells. Stem Cell Rep 1:66-78.

60. Ginsburg M, MH Snow and A McLaren. (1990). Primordial germ cells in the mouse embryo during gastrulation. Development 110:521-528.

61. Eguizabal C, TC Shovlin, G Durcova-Hills, A Surani and A McLaren. (2009). Generation of primordial germ cells from pluripotent stem cells. Differentiation 78 : 116-123.
62. Reik W and J Walter. (2001). Genomic imprinting: parental influence on the genome. Nat Rev Genet 2:21-32.

63. Hayashi K and MA Surani. (2009). Resetting the epigenome beyond pluripotency in the germline. Cell Stem Cell 4:493-498.

64. Wylie C. (1999). Germ cells. Cell 96:165-174.

65. Hayashi K, SM de Sousa Lopes and MA Surani. (2007). Germ cell specification in mice. Science 316:394-396.

66. Ratajczak MZ, DM Shin, G Schneider, J Ratajczak and M Kucia. (2013). Parental imprinting regulates insulin-like growth factor signaling: a Rosetta Stone for understanding the biology of pluripotent stem cells, aging and cancerogenesis. Leukemia 27:773-779.

67. Melcer S and E Meshorer. (2010). Chromatin plasticity in pluripotent cells. Essays Biochem 20:245-262.

68. Bhartiya D, S Kasiviswananthan and A Shaikh. (2012). Cellular origin of testis-derived pluripotent stem cells: a case for very small embryonic-like stem cells. Stem Cells Dev 21:670-674.

69. Ratajczak MZ, M Suszynska, D Pedziwiatr, K Mierzejewska and NJ Greco. (2012). Umbilical cord bloodderived very small embryonic like stem cells (VSELs) as a source of pluripotent stem cells for regenerative medicine. Pediatr Endocrinol Rev 9:639-643.

70. Ratajczak MZ, EK Zuba-Surma, B Machalinski, J Ratajczak and M Kucia. (2008). Very small embryonic-like (VSEL) stem cells: purification from adult organs, characterization, and biological significance. Stem Cell Rev 4:89-99.

71. Sandhya A, D Bhartiya, K Sriraman, H Patel, D Manjramkar, G Bakshi, V Dhamankar and P Kurkure. (2013). Quiescent very small embryonic-like stem cells resist oncotherapy and can restore spermatogenesis in germ cell depleted mammalian testis. Stem Cells Dev [Epub ahead of print]; DOI:10.1089/scd.2013.0059.

72. Kucia M, B Dawn, G Hunt, Y Guo, M Wysoczynski, M Majka, J Ratajczak, F Rezzoug, ST Ildstad, R Bolli and MZ Ratajczak. (2004). Cells expressing early cardiac markers reside in the bone marrow and are mobilized into the peripheral blood after myocardial infarction. Circ Res 95:1191-1199.

73. Ratajczak J, DM Shin, W Wan, R Liu, MM Masternak, K Piotrowska, B Wiszniewska, M Kucia, A Bartke and MZ Ratajczak. (2011). Higher number of stem cells in the bone marrow of circulating low Igf-1 level Laron dwarf mice-novel view on Igf-1, stem cells and aging. Leukemia 25:729-733.

74. Kucia M, DM Shin, R Liu, J Ratajczak, E Bryndza, MM Masternak, A Bartke and MZ Ratajczak. (2011). Reduced number of VSELs in the bone marrow of growth hormone transgenic mice indicates that chronically elevated Igf1 level accelerates age-dependent exhaustion of pluripotent stem cell pool: a novel view on aging. Leukemia 25:1370 1374.

75. Kucia M, M Masternak, R Liu, DM Shin, J Ratajczak, K Mierzejewska, A Spong, JJ Kopchick, A Bartke and MZ Ratajczak. (2013). The negative effect of prolonged somatotrophic/insulin signaling on an adult bone marrowresiding population of pluripotent very small embryoniclike stem cells (VSELs). Age (Dordr) 35:315-330.

76. Orlic D, J Kajstura, S Chimenti, DM Bodine, A Leri and P Anversa. (2003). Bone marrow stem cells regenerate infarcted myocardium. Pediatr Transplant 7 (Suppl. 3): 86-88. 
77. Mezey E and KJ Chandross. (2000). Bone marrow: a possible alternative source of cells in the adult nervous system. Eur J Pharmacol 405:297-302.

78. Prockop DJ. (2003). Further proof of the plasticity of adult stem cells and their role in tissue repair. J Cell Biol 160:807-809.

79. Wagers AJ and IL Weissman. (2004). Plasticity of adult stem cells. Cell 116:639-648.

80. Mezey E, KJ Chandross, G Harta, RA Maki and SR McKercher. (2000). Turning blood into brain: cells bearing neuronal antigens generated in vivo from bone marrow. Science 290:1779-1782.

81. Vassilopoulos G and DW Russell. (2003). Cell fusion: an alternative to stem cell plasticity and its therapeutic implications. Curr Opin Genet Dev 13:480-485.

82. Scott EW. (2004). Stem cell plasticity or fusion: two approaches to targeted cell therapy. Blood Cells Mol Dis 32:65-67.

83. Eisenberg LM and CA Eisenberg. (2003). Stem cell plasticity, cell fusion, and transdifferentiation. Birth Defects Res C Embryo Today 69:209-218.

84. Ratajczak MZ, EK Zuba-Surma, W Wojakowski, J Ratajczak and M Kucia. (2008). Bone marrow-home of versatile stem cells. Transfus Med Hemother 35:248-259.

85. Kassmer SH and DS Krause. (2013). Very small embryoniclike cells: Biology and function of these potential endogenous pluripotent stem cells in adult tissues. Mol Reprod Dev 80:677-690.

86. Anjos-Afonso F and D Bonnet. (2007). Nonhematopoietic/ endothelial SSEA-1 + cells define the most primitive progenitors in the adult murine bone marrow mesenchymal compartment. Blood 109:1298-1306.

87. Cesselli D, AP Beltrami, S Rigo, N Bergamin, F D’Aurizio, R Verardo, S Piazza, E Klaric, R Fanin, et al. (2009). Multipotent progenitor cells are present in human peripheral blood. Circ Res 104:1225-1234.

88. Kajstura J, M Rota, SR Hall, T Hosoda, D D'Amario, F Sanada, H Zheng, B Ogorek, C Rondon-Clavo, et al. (2011). Evidence for human lung stem cells. N Engl J Med 364:1795-1806.

89. Atari M, M Barajas, F Hernandez-Alfaro, C Gil, M Fabregat, E Ferres Padro, L Giner and N Casals. (2011). Isolation of pluripotent stem cells from human third molar dental pulp. Histol Histopathol 26:1057-1070.

90. Wang X, H Ouyang, Y Yamamoto, PA Kumar, TS Wei, R Dagher, M Vincent, X Lu, AM Bellizzi, et al. (2011). Residual embryonic cells as precursors of a Barrett's-like metaplasia. Cell 145:1023-1035.

91. d'Aquino R, V Tirino, V Desiderio, M Studer, GC De Angelis, L Laino, A De Rosa, D Di Nucci, S Martino, et al. (2011). Human neural crest-derived postnatal cells exhibit remarkable embryonic attributes either in vitro or in vivo. Eur Cell Mater 21:304-316.

92. Andreadis D, A Bakopoulou, G Leyhausen, A Epivatianos, J Volk, A Markopoulos and W Geurtsen. (2013). Minor salivary glands of the lips: a novel, easily accessible source of potential stem/progenitor cells. Clin Oral Investig [Epub ahead of print]; DOI:10.1007/s00784-013-1056-6.

93. Roy S, P Gascard, N Dumont, J Zhao, D Pan, S Petrie, M Margeta and TD Tlsty. (2013). Rare somatic cells from human breast tissue exhibit extensive lineage plasticity. Proc Natl Acad Sci USA 110:4598-4603.

94. Murrell W, E Palmero, J Bianco, B Stangeland, M Joel, L Paulson, B Thiede, Z Grieg, I Ramsnes, et al. (2013).
Expansion of multipotent stem cells from the adult human brain. PLoS One 8:e71334.

95. Stimpfel M, T Skutella, B Cvjeticanin, M Meznaric, P Dove, S Novakovic, P Cerkovnik, E Vrtacnik-Bokal and I Virant-Klun. (2013). Isolation, characterization and differentiation of cells expressing pluripotent/multipotent markers from adult human ovaries. Cell Tissue Res 354:593-607.

96. Dyce PW, J Liu, C Tayade, GM Kidder, DH Betts and J Li. (2011). In vitro and in vivo germ line potential of stem cells derived from newborn mouse skin. PLoS One 6:e20339.

97. Song SH, BM Kumar, EJ Kang, YM Lee, TH Kim, SA Ock, SL Lee, BG Jeon and GJ Rho. (2011). Characterization of porcine multipotent stem/stromal cells derived from skin, adipose, and ovarian tissues and their differentiation in vitro into putative oocyte-like cells. Stem Cells Dev 20:1359-1370.

98. Shirazi R, AH Zarnani, M Soleimani, MA Abdolvahabi, K Nayernia and I Ragerdi Kashani. (2012). BMP4 can generate primordial germ cells from bone-marrow-derived pluripotent stem cells. Cell Biol Int 36:1185-1193.

99. Johnson J, J Bagley, M Skaznik-Wikiel, HJ Lee, GB Adams, Y Niikura, KS Tschudy, JC Tilly, ML Cortes, et al. (2005). Oocyte generation in adult mammalian ovaries by putative germ cells in bone marrow and peripheral blood. Cell 122:303-315.

100. Selesniemi K, HJ Lee, T Niikura and JL Tilly. (2009). Young adult donor bone marrow infusions into female mice postpone age-related reproductive failure and improve offspring survival. Aging (Albany NY) 1:49-57.

101. Nayernia K, JH Lee, N Drusenheimer, J Nolte, G Wulf, R Dressel, J Gromoll and W Engel. (2006). Derivation of male germ cells from bone marrow stem cells. Lab Invest 86:654-663.

102. Heo YT, SH Lee, JH Yang, T Kim and HT Lee. (2011). Bone marrow cell-mediated production of transgenic chickens. Lab Invest 91:1229-1240.

103. Hua J, H Yu, W Dong, C Yang, Z Gao, A Lei, Y Sun, S Pan, Y Wu and Z Dou. (2009). Characterization of mesenchymal stem cells (MSCs) from human fetal lung: potential differentiation of germ cells. Tissue Cell 41:448455.

104. Beltrami AP, D Cesselli, N Bergamin, P Marcon, S Rigo, E Puppato, F D'Aurizio, R Verardo, S Piazza, et al. (2007). Multipotent cells can be generated in vitro from several adult human organs (heart, liver, and bone marrow). Blood 110:3438-3446.

105. Jiang Y, BN Jahagirdar, RL Reinhardt, RE Schwartz, CD Keene, XR Ortiz-Gonzalez, M Reyes, T Lenvik, T Lund, et al. (2002). Pluripotency of mesenchymal stem cells derived from adult marrow. Nature 418:41-49.

106. Jiang Y, B Vaessen, T Lenvik, M Blackstad, M Reyes and CM Verfaillie. (2002). Multipotent progenitor cells can be isolated from postnatal murine bone marrow, muscle, and brain. Exp Hematol 30:896-904.

107. Kogler G, S Sensken, JA Airey, T Trapp, M Muschen, N Feldhahn, S Liedtke, RV Sorg, J Fischer, et al. (2004). A new human somatic stem cell from placental cord blood with intrinsic pluripotent differentiation potential. J Exp Med 200:123-135.

108. D’Ippolito G, S Diabira, GA Howard, P Menei, BA Roos and PC Schiller. (2004). Marrow-isolated adult multilineage inducible (MIAMI) cells, a unique population of 
postnatal young and old human cells with extensive expansion and differentiation potential. J Cell Sci 117:29712981.

109. Ratajczak MZ, E Zuba-Surma, M Kucia, A Poniewierska, M Suszynska and J Ratajczak. (2012). Pluripotent and multipotent stem cells in adult tissues. Adv Med Sci 57:1-17.

110. Kuroda Y, S Wakao, M Kitada, T Murakami, M Nojima and M Dezawa. (2013). Isolation, culture and evaluation of multilineage-differentiating stress-enduring (Muse) cells. Nat Protoc 8:1391-1415.

111. Wakao S, M Kitada, Y Kuroda, T Shigemoto, D Matsuse, H Akashi, Y Tanimura, K Tsuchiyama, T Kikuchi, et al. (2011). Multilineage-differentiating stress-enduring (Muse) cells are a primary source of induced pluripotent stem cells in human fibroblasts. Proc Natl Acad Sci USA 108:98759880.

112. Le Blanc K and M Pittenger. (2005). Mesenchymal stem cells: progress toward promise. Cytotherapy 7:36-45.

113. Li L and H Clevers. (2010). Coexistence of quiescent and active adult stem cells in mammals. Science 327: $542-545$.

114. Venkatraman A, XC He, JL Thorvaldsen, R Sugimura, JM Perry, F Tao, M Zhao, MK Christenson, R Sanchez, et al. (2013). Maternal imprinting at the H19-Igf2 locus maintains adult haematopoietic stem cell quiescence. Nature 500:345-349.

115. Nadri S, B Kazemi, MB Eslaminejad, S Yazdani and M Soleimani. (2013). High yield of cells committed to the photoreceptor-like cells from conjunctiva mesenchymal stem cells on nanofibrous scaffolds. Mol Biol Rep 40:3883-3890.

116. Nadri S, S Yazdani, E Arefian, Z Gohari, MB Eslaminejad, B Kazemi and M Soleimani. (2013). Mesenchymal stem cells from trabecular meshwork become photoreceptor-like cells on amniotic membrane. Neurosci Lett 541:43-48.

117. Bhartiya D, S Unni, S Parte and S Anand. (2013). Very small embryonic-like stem cells: implications in reproductive biology. Biomed Res Int 2013:682326.
118. Anand S, D Bhartiya, K Sriraman, H Patel, D Manjramkar, G Bakshi, V Dhamankar and P Kurkure. (2013). Quiescent very small embryonic-like stem cells resist oncotherapy and can restore spermatogenesis in germ cell depleted mammalian testis. Stem Cells Dev [Epub ahead of print]; DOI:10.1089/scd.2013.0059.

119. Jones RJ, JE Wagner, P Celano, MS Zicha and SJ Sharkis. (1990). Separation of pluripotent haematopoietic stem cells from spleen colony-forming cells. Nature 347:188-189.

120. Habich A, M Jurga, I Markiewicz, B Lukomska, U BanyLaszewicz and K Domanska-Janik. (2006). Early appearance of stem/progenitor cells with neural-like characteristics in human cord blood mononuclear fraction cultured in vitro. Exp Hematol 34:914-925.

121. Chang YJ, KF Tien, CH Wen, TB Hsieh, and SM Hwang. (2013). Recovery of CD45-/Lin-/SSEA-4 + very small embryonic-like stem cells by cord blood bank standard operating procedures. Cytotherapy [Epub ahead of print]; DOI:10.1016/j.jcyt.2013.10.009.

122. Havens A, H Sun, Y Shiozawa, Y Jung, J Wang, A Mishra, Y Jiang, DW O’Neill, PH Krebsbach et al. (2013). Human and murine very small embryonic-like (VSEL) cells represent multipotent tissue progenitors, in vitro and in vivo. Stem Cells Dev [Epub ahead of print]; DOI:10.1089/scd.2013.0362.

Address correspondence to:

Prof. Mariusz Z. Ratajczak

Stem Cell Institute at James Graham Brown Cancer Center University of Louisville 500 South Floyd Street, Room 107 Louisville, KY 40202

E-mail: mzrata01@louisville.edu

Received for publication September 27, 2013 Accepted after revision November 27, 2013

Prepublished on Liebert Instant Online December 3, 2013 